\title{
A Segurança Nacional e a Legislação Brasileira
}

\author{
ANTÔNIO DE ARRUDA \\ Magistrado e Professor da Escola \\ Superior de Guerra
}

SUMÁRIO: 1 - Introdução. 2 - Um Problema Semântico: Fria e Guerra Revolucionária. 4 - Estrégia Direta e Indireta. Guerra 5 - Fatores Adversos. Antagonismos - Conceito Atual de Segurança. Nacional na Constituição do Brasil. Pressões. 6-A Segurança Nacional. 8 - A Interpretação Brasil. 7 - A Lei de Segurança pretação do Supremo Tribunal Federal. 9

Em artigo anterior, ${ }^{1}$ focalizamos a a ciência e a arte de fixar os Objos a Política Nacional como a sua conquista e preservação. a. Segundo esse entendimento, a na fixação de Objetivos, considecisão, que, no caso, implica ção de interesses e aspirações cam-se cs Objetivos Nacionais nacionais. Dentre eles, destabilidade, que compreendem interesses entes, de relativa estacompõem as forças de evoluçãosses e aspirações vitais e que sociedade.

Numa enumeração exemplificativa, teríamos como Objetivos Nacionais Permanentes a integridade territorial, a integração nacional, a soberania, o desenvolvimento, a democracia e a paz social. Alguns desses Objetivos poderão estar conquistados, como a integridade territorial e a soberania; urge apenas preservá-los. Outros dependem de aprimoramento, como a democracia, a integração nacional e o desenvolvimento. Ao passo

1 Rev. do Serv. Público - DASP - vol. 105, no 2, maio/agosto 1970. 
que outros serão resultantes da efetivação dos demais, como
a paz social.

Como etapas intermediárias, força é criarem-se Objetivos mais ao alcance da capacidade do Poder Nacional, ou seja, os Objetivos Nacionais Atuais.

Tendo em vista os Objetivos, formulam-se também diretrizes, planos e programas que estimulem o progresso nacional e criem condições para que este se concretize. Daí os dois aspectos da Política Nacional: a segurança e o desenvolvimento.

O nosso tema, agora, será o da segurança nacional.

\section{2 - UM PROBLEMA SEMÂNTICO: DEFESA E SEGURANÇA}

A Constituição do Império usava, de preferência, o termo segurança. Assim, o art. $112 \S 15$, estabelecia como atribuição do Imperador, na qualidade de Chefe do Poder Executivo, "prover a tudo que for concernente à segurança interna e externa do Estado". Também o art. 177 , § 35 , previa a suspensão dos direitos individuais, quando o exigisse a segurança do Estado", nos casos de rebelião ou de invasão de inimigos. ${ }^{2}$ As Constituições republicanas posteriores deram ênfase
à palavra defesa, mas na Constituição vigente voltou a predo-
minar o termo segurança. minar o termo segurança.

Como se vê, segurança e defesa são palavras intercorrentes, sujeitas a variações semânticas, não peculiares à nossa língua. Ao contrário, sofremos influência do que aconteceu alhures, em face de acontecimentos históricos ligados ao pro-
blema da guerra, que vamos recapitular.

$\mathrm{Na}$ Batalha de Valmy, em 20 de setembro de 1792, defrontaram-se os prussianos, chefiados pelo Duque de BrunsBrunswick, sobrinho de Frederico, o Grande, cuja reputação provinha de ganhar batalhas sem derramamento de sangue, reuniu o seu estado-maior e proferiu a sua decisão: "Não com-

2 Também o art 148

e terra para "segurança estabelecia o emprego da força armada de mar os Ministros de Estado são respon do Império"; o art. 133, § 50, dizia que dade, segurança ou propriedadensáveis "pelo que obrarem contra a liberdos direitos civis e políticos dos cidadãos"; e o art. 179, que tratava base a liberdade, a seguran dos cidadãos, estatuía que estes têm "por 
bateremos aqui!" Manobrou o seu exército e habilmente o retirou do campo de batalha, em que só se ouviram alguns ca-
nhoneios.

No dia seguinte, Goethe, testemunha desse lance, disse: "Neste lugar e a partir desta data, tem início uma era da história universal, e todos aqui presentes poderão dizer que as-
sistiram ao seu advento."

E o Marechal Foch resumiu o significado dessa batalha, que não houve, com as palavras: "As guerras dos reis chega-
ram a seu fim; tinha início a guerra dos povos."3

Um decreto, baixado pela Convenção de 23 de agosto de 1793, marcava o começo dos novos tempos:

"A partir deste momento até o instante em que nossos inimigos forem expulsos do território da República, todos os franceses estão permanentemente convocados para o serviço das armas. Os jovens combaterão; os casados forjarão as armas e transportarão os suprimentos; as mulheres farão as barracas e as roupas e servirâo nos hospitais; as crianças transformarão pedaços de linho usado em ataduras; os velhos irão para as praças públicas, a fim de estimular a coragem dos combaas armas de fogo de calibre adequado serão entregues às tropas; o serviço no interior será feito com armas brancas e de

Este decreto assinala o surgimento da chamada guerra total. Naquele instante, como o país estava ocupado por inimigos, todas as forças vivas da nacionalidade foram chamadas a combatê-lo. Era a "nação em armas", o engajamento universal, pela defesa nacional." "Todos os franceses são responsáveis

Mas, advirta-se, defesa, aqui, prende-se a um sentido estritamente militar. E um conceito que põe ênfase nas perspectivas de agressão externa, cuja repulsa cabe às Forças Armadas. E é um conceito que se identificou com os tempos em que

3 J. F. C. Fuller, A Conduta da Guerra, trad. de Hermann Bergovist, Biblioteca do Exército, 1966, pp. 20-21. 4 J. F. C. Fuller, ob. cit. Ver também Arnold Toynbee, A Study of 
Com o aparecimento de novas formas de conflitos, houve sutil evolução semântica, com referência à defesa e à segurança. Evolução semelhante ocorreu com a palavra estratégia. ${ }^{5}$

\section{3 - ESTRATÉGIA DIRETA E INDIRETA. GUERRA FRIA E GUERRA REVOLUCIONÁRIA} doutrinalisando as guerras napoleônicas, Clausewitz criou uma vo, que que exaltava a batalha, incentivando o espírito ofensica da "batalhou a estratégia até a 2" Grande Guerra. A busobjetivos fundamisiva" e o aniquilamento do inimigo seriam os é o preço da vitória", sem medir sacrifícios, pois o "sangue

Depois de examinar 25 séculos de guerras, Liddell Hart salienta que este ataque direto só conseguiu resultados satisfatórios em 6 batalhas. Para Liddell Hart, a estratégia produtiva é a que emprega meios indiretos, e o bom estrategista é aquele que sabe forçar o desequilíbrio do adversário, de modo que, como no jiu-jitsu, seu próprio esforço seja transformado na alavanca que determinará a sua queda. ${ }^{6}$

As formas indiretas da estratégia, levadas às últimas conseqüências, com o absoluto abandono dos princípios éticos, têm servido aos regimes de força, nos seus desígnios de do-
minação mundial.

Hitler afirmara: "Existe uma estratégia mais ampla, a que emprega armas intelectuais... Por que iria eu desmoralizar o inimigo com meios militares, se posso fazê-lo melhor e mais barato com outros meios? Nossa estratégia consiste em destruir o inimigo por dentro e conquistá-lo utilizando os recursos de que ele próprio dispõe."'

Esta "corrosão desde o interior", empregada, com tanto êxito, pelo nazismo na conquista de povos vizinhos, assemelhage à estratégia soviética, adotada depois, com requintes e larComo precursor de Hitler, Lenin já sentenciava: "A estra-
tégia mais segura é aquela que procura retardar as operações

5 Inicialmente, a estratégia era a "arte dos generais", circunscrita a âmbito militar. Depois, com a doutrina de Clausewitz, passou a abrange: também os campos político e psicossocial Hoje, considera-se a estraté e psicossocial e, mais tarde, o econômico. isto é, todos os restratégia como a arte de aplicar o Poder Nacional, dos objetivos fixados

C Lifdellítica Nacional.

7 In Liddart, As Grandes Guerras da História, pp. 165, 166 e XVII.

In Liddell Hart, ob. cit., p. 239. 
até que a desintegração moral do inimigo torne o seu desencadeamento um golpe ao mesmo tempo possível e fácil."8

Foi Churchill o primeiro a surpreender o método soviético, com a sua famosa advertência: "De Stettin, no Báltico, a Trieste, no Adriático, desceu uma cortina de ferro sobre o Continente... Não acredito que a Rússia Soviética deseje a guerra. O que deseja são os frutos da guerra e a expansão indefinida de seu poderio e de suas doutrinas.",

Era a guerra fria que começava. Por sua vez, Vichinsky foi muito claro e incisivo ao afirmar, nas Nações Unidas, em 1954: "Nós não venceremos o Ocidente por meio de bomba atômica. Nós venceremos o Ocidente com qualquer coisa que O Ocidente não compreende: as nossas cabeças, as nossas idéias, as nossas doutrinas."10

A tônica desta nova e sutil modalidade de conflito reside em minar o organismo nacional, levando-o a desagregar-se pela destruição dos seus valores fundamentais e da sua capacidade criadora. Trata-se de uma agressão ideológica, desencadeada tenazmente pelo marxismo-leninismo, a qual desconhece fronteiras e procura invadir não territórios, mas mentes desprotegidas, abalando convicções, atingindo, em profundidade, todo o complexo político, social e econômico da nacionalidade.

Trata-se, enfim, da chamada guerra revolucionária, ${ }^{11}$ que engloba todos esses processos indiretos de dominação, antes do uso da força.

The "O campo de ação da guerra revolucionária" - ensina ção, cur Arnold - "é, antes de tudo, a consciência da populademais conquista é essencial para o domínio de todos os ráter deampos de luta, armada ou não. Revestindo-se do caatravés guerra total, a ação revolucionária procura o êxito sos militares."'12

8 In Liddell Hart, ob. cit., p. 239.

Edit. In Thomas Wilson Jr., Guerra Fria e Bom Senso, trad. de G. Rebuá, 10 anema, Rio, 1964, p. 24.

gurança In Equipe da ESG, A Democracia Brasileira, revista da ADESG Se11 Desenvolvimento, $n$ ? 134,1969, p. 9.

guerra (quzemos a "chamada guerra revolucionária" porque não se trata de

clusive que pressupõe a adoção de princípios de Direito Internacional, in-

- aprimo direito de beligerância), nem de revolução (que envolve evolução

pressão, favento). Os marxistas-leninistas impingiram, porém, o uso da ex12 favorável aos seus desígnios, e hoje seria difícil mudá-la.

In Bilac Pinto, Guerra Revolucionária, Forense, p. 180. 
Com estas premissas é fácil compreender o conceito dado pelo Estado-Maior das Forças Armadas:

"Guerra revolucionária é a guerra interna de concepção marxista-leninista, de possivel adoção por movimentos revolucionários diversos, que - apoiados em uma ideologia, estimulados e, até mesmo, auxiliados do exterior - visam à conquista do poder, através do controle progressivo, físico e espiritual da população sobre que é desencadeada, desenvolvendo-se segundo processo determinado, com a ajuda de técnicas parta."'13

\section{4 - CONCEITO ATUAL DE SEGURANÇA}

Contra o perigo permanente de desagregação e destruição, guerra revolucionária, as forças militares se tornaram insufiprova-se com o que se verifica em toda parte, inclusive nas grandes potências. Os Estados Unidos, por exemplo, após amargarem, na área externa, afrontas humilhantes, como no episódio da apreensão do navio "Pueblo" pelos coreanos-donorte, se mostram incapazes, às vezes, de manter, a contento, a ordem interna. Os distúrbios de várias origens, inclusive os inspirados pelos marxistas-leninistas, alastram-se, às vezes, pelo
país de maneira incontrolável.

Viu-se, pois, que não bastava a defesa, simplesmente, mas

seria necessária alguma coisa mais positiva e eficaz.
Surgiu daí a noção de segurança, tado de alerta deção de segurança, entendida como um eso perigo não amevenção, de consciência do perigo. E como forçoso é que estaça apenas o indivíduo, mas a nação inteira, vendo o já citado se ponha em guarda como um todo. ReviDOS SÃO RESP decreto napoleônico, poder-se-á dizer: "TO-

O Marech rida na Escola Sustello Branco, em sua aula inaugural profebem este novo cuperior de Guerra, em março de 1967, resumiu gente (que o de deito: "A noção de segurança é mais abranglobal das instituicesa). Comprende, por assim dizer, a defesa cossociais, a preser, incorporando, por isso, os aspectos psipolítica interna." 14 ação do desenvolvimento e da estabilidade

13 In Bilac Pinto, ob. cit., p. 112.
14 In Segurança e Desenvolvimento

Doc. da ESG-C-01-67, p. 2. 
Por outro lado, o General Lyra Tavares assim se expressa a esse respeito: "Além da guerra, por assim dizer, ostensiva, é preciso considerar que o organismo do Estado e, conseqüentemente, a sua soberania podem ser solapados e destruídos por ações que chamaríamos de "invisiveis", ou não positivamente caracterizáveis como de agressão, mediante as quais é possível, senão destruí-lo, pelo menos dominá-lo nos seus elementos essenciais." $E$, procurando distinguir segurança de defesa, acrescenta: "Segurança é um estado, ao passo que defesa é um ato - ou um conjunto de atos - diretamente ligado a determinado tipo de ameaça caracterizada e medida. A tefesa organiza-se para o fim especial de repelir um ataque previsto, ao passo que a segurança, no sentido em que a encaramos, é estabelecida como cobertura integral contra qualquer tipo de ameaça que ela própria - a segurança - torna inoperante e desencoraja." 15

A segurança é, pois, uma situação de garantia de que desfruta uma nação contra as ameaças aos seus valores vitais. Um Estado terá propiciado à comunidade um razoável grau de segurança quando estiver em condições de anular essas ameaças.

Podemos, então, conceituar:

"Segurança nacional é o grau de garantia que, através de ações políticas, econômicas, psicossociais e militares, o Estado proporciona à comunidade para a conquista e manutenção dos Objetivos Nacionais, a despeito dos antagonismos ou pressões, existentes ou potenciais."

\section{5 - FATORES ADVERSOS. ANTAGONISMOS E PRESSÕES}

No conceito de segurança, expresso anteriormente, se insere um outro - de antagonismos e pressões -, que exige esclarecimento.

Em verdade, um política de segurança (como também a de desenvolvimento), deve prever a existência de óbices que se antepõem à sua execução. A noção de segurança se prende à necessidade de se fazer face a esses óblices.

Chamamos, em geral, fatores adversos aos obstáculos que dificultam a realização da Política Nacional - seja de desen15 Gen. Lyra Tavares, Segurança Nacional, Problemas Atuais - José
Alvaro Ed., pp. 98 e 101. 
volvimento, seja de segurança. A seca do Nordeste, as inundações são fatores adversos. Mas, se há uma atitude intencional, deliberada e contestatória à consecução ou manutenção dos Objetivos Nacionais, o fator adverso toma o nome particular de antagonismo. Quanto às pressões, nascem de antagonismos que dispõem de poder.

Teremos, então, em termos mais explícitos:

FATORES ADVERSOS são obstáculos de toda ordem, internos ou externos, assinaláveis em determinada conjuntura, que dificultam os esforços do Estado para a consecução ou manutenção dos Objetivos Nacionais.

ANTAGONISMOS são fatores adversos de modalidade peculiar, por manifestarem atividade deliberada, intencional e contestatória à consecução ou manutenção dos Objetivos Nacionais.

PRESSÕES são poderes emanados de um ou mais antagonismos, ou por estes estimulados, que atuam contrária e contestatoriamente à consecução ou manutenção dos Objetivos Nacionais.

Dentre as pressões, há aquelas de tal forma ponderáveis e importantes que podem até impedir a consecução ou manutenção dos Objetivos Nacionais. São as pressões dominantes, cuja superação exige esforço extraordinário do Estado, forçando, às vezes, o recurso à guerra.

\section{6 - A SEGURANÇA NACIONAL NA} CONSTITUIÇÃO DO BRASIL

A Constituição vigente deu ênfase especial ao problema da segurança no sentido em que a estamos focalizando. O seu texto consigna, em geral, o termo segurança nos lugares em que antigamente se falava em defesa. É o que se pode verificar no art. 4\%, I, 16 que inclui, dentre os bens da União, a parte de terras devolutas indispensável à segurança nacional; no art. 92, que determina a obrigatoriedade do serviço militar e outros encargos necessários à segurança nacional etc. Outros dispositivos tratam também, eventualmente, da se-
gurança, tais como:

- $\mathrm{O}$ art. $80, \mathrm{~V}$, que estabelece a competência da União rança nacion e promover o desenvolvimento e a segu-

cional já Esta e outras citações subseqüentes se referem ao texto constitu- 
- O art. 8 , VIII, b, que fixa a competência da Policia Federal para apurar infrações penais contra a segurança nacional.

- 0 art. 32, que prescreve a cessação da inviolabilidade dos congressistas nos casos de crimes previstos na Lei de Segurança Nacional.

- O art. 55, que dá competência ao Presidente da República para expedir decretos-leis sobre segurança nacional, em casos de urgência ou de interesse público relevante (dispositivo que ainda voltaremos a examinar).

- O art. 129, $\S 1$ \%, que estende aos civis o foro da Justiça Militar para repressão dos crimes contra a segurança nacional, nos casos expressos em lei.

Mas a inovação maior está na Seção V do Capítulo VII, que põe em destaque a segurança nacional, tirando-a do âmbito das Forças Armadas para colocá-la na faixa do Poder Executivo.

O art. 86 dispõe: "Toda pessoa, natural ou jurídica, é responsável pela segurança nacional, nos limites definidos em lei."

Este preceito suscitou grande celeuma, ao surgir no texto constitucional de 1967. ${ }^{17}$ Argumentava-se, então, que, se toda pessoa natural é responsável pela segurança, chegar-se-ia ao absurdo de que até as crianças estariam sujeitas aos "encargos militares". E as pessoas jurídicas, como participariam da segurança nacional?

Informa Paulo Sarasate que, outorgada a Constituição, foram, a seguir, apresentadas emendas ao Congresso propondo a supressão do dispositivo. Sustentou-se até na época que se pretendia impor a transformação de cada cidadão num "agente de segurança". 18

Esta perplexidade, que ainda perdura, em parte, nasce do desconhecimento do conceito atual de segurança e de sua colocação apenas no campo militar. Entretanto, quando o texto constitucional proclama a participação de todos na segurança nacional, tem em vista o seu entendimento mais amplo, na

dos por No Estado de Israel, com menos de 3 milhões de habitantes, cercadetermina 80 milhões de inimigos, seria desnecessário um dispositivo legal obriga a do que todos são responsáveis pela segurança nacional. O perigo defesa.

tas Bastos, Paulo Sarasate, A Constituição do Brasil ao Alcance de Todos, Frei- 
conformidade do que acabamos de expor. Além disso, os termos dessa participação serão fixados pela lei ordinária, a qual, evidentemente, deverá atender, sobretudo, às medidas preventivas, eliminando óbices que possam trazer perturbações à comunidade nacional.

Um exemplo esclarecerá a nossa assertiva. O analfabetismo é um fator adverso, que entrava o desenvolvimento e pode causar problemas à segurança, gerando antagonismo, desde que elementos subversivos se sirvam da massa inculta para os seus intentos de provocação de distúrbios sociais. Ora, cocional, poderão ser chamadas a cooperar na luta contra a ignorância. Daí o sentido do preceito constitucional que sujeitou primária. Muitos empresários se sensibilizaram por este problema e acataram, de bom grado, o mandamento constitucional. taxas de educão fizeram, o que levou o legislador a criar

de outro modo o assunto. salário juco raciocínio poderíamos aplicar aos problemas do nacional sabalhador na riqueza empresa modros que evidenciam o sentido participante da de lucros.

Assim, é vasto o campo em que se estende a segurança nacional. Às vezes, ela penetra a área do desenvolvimento, propiciando entre ambos uma interdependência constante e fazendo com que se torne muito sutil a delimitação entre as
duas concepcões.

CONSELHO DE SEGURANÇA NACIONAL

Os arts. 87 e seguintes se referem ao Conselho de Segurança Nacional. Este órgão é antigo, de longa tradição nas Forças Armadas, pois foi criado em 1927 (Dec. no 17.999), sob a denominação de Conselho de Defesa Nacional. Hoje, está estruturado em novos moldes, como órgão de mais alto nível na e execução direta ao Presidente da República, para a formulação

-

mais importanterimina a competência do Conselho, sendo a

19 A Constituição de 1934

Conselho de Segurança Nacional já mudara a denominação do órgão para Constituição de 1946 reproduziual, fazendo ressurgir o termo (art. 159). A tudo, predominou em ambaziu a mesma denominação (arts. 179-180). Con- 
Permanentes e das bases para a Política Nacional. Estuda ainda os assuntos relacionados com a segurança e indica as áreas indispensáveis à segurança, bem como os municípios considerados do interesse desta, cujos prefeitos serão nomeados pelos governadores dos Estados, ouvido o Conselho (art. 15, § 1?, letra b).

Esta estrutura é a predominante na atualidade. Nos Estados Unidos, por exemplo, existe o Department of Defense, que é o maior órgão na esfera do Poder Executivo, com a responsabilidade de formular a política militar e manter as Forças Armadas do país. Há também o National Security Council, órgão de estado-maior, criado em 1947, junto ao Gabinete do Presidente da República, que o assessora nas questões internas ou externas que envolvam a segurança nacional. A função principal deste Conselho é avaliar e fixar os objetivos, compromissos e riscos dos Estados Unidos no interesse da segurança nacional e opinar sobre políticas e decisões específicas a serem tomadas pelo Presidente. ${ }^{20}$

\section{7 - A LEI DE SEGURANÇA NACIONAL}

O Decreto-Lei no 898, de 29 de setembro de 1969, define os crimes contra a segurança nacional, a ordem política e social e, como fizera o Decreto-Lei n? 314 , de 13 de março de 1967, após reproduzir o preceito constitucional de que toda pessoa natural ou jurídica é responsável pela segurança nacional, traz alguns conceitos básicos sobre o assunto.

A segurança nacional, esse decreto-lei a define como a "garantia da consecução dos Objetivos Nacionais contra antagonismos tanto internos como externos" (art. 2\%).

$\mathrm{O}$ art. 3 ? dinamiza o conceito de segurança nacional, esclarecendo que compreende medidas destinadas à preservação dos dois aspectos em que se divide - segurança externa e segurança interna - e que nessas medidas se incluem a prevenção e a repressão da guerra psicológica e da guerra revolucionária ou subversiva.

Os parágrafos seguintes definem a segurança interna e as novas modalidades de conflitos mencionados no corpo do artigo.

A segurança interna, integrada na segurança nacional, diz respeito às ameaças ou pressões antagônicas de qualquer ori-

20 In Jack e Milton Greenberg, The American Political Dictionary, Western Michigan Univ., 1966, pp. 334 e 335. 
gem, forma ou natureza que se manifestem ou produzam efeito
no País

A guerra psicológica adversa é o emprego da propaganda, da contrapropaganda e de ações nos campos político, econômico, psicossocial e militar, com a finalidade de influenciar ou provocar opiniões, emoções, atitudes e comportamentos de grupos estrangeiros, inimigos, neutros ou amigos, contra a consecução dos Objetivos Nacionais.

Trata-se, aqui, daquela "corrosão desde o interior", a que nos referimos no item 3 , de que se serviu o nazismo, antes, e da guerra revolucionária.

Quanto à guerra revolucionária, preceitua o $\S 3$ ? que é o conflito interno, geralmente inspirado em uma ideologia, ou auxiliado do exterior, que visa à conquista subversiva do poder pelo controle progressivo da Nação.

Este é um conceito resumido do que fora adotado pelo EMFA, que citamos no item 3 , in fine.

\section{CRITICAS À LEI DE SEGURANÇA}

As definições contidas na Lei de Segurança estão longe de terem entendimento pacífico.

Examinando os preceitos dessa lei, o Senador Josaphat Marinho os contesta, afirmando que "antagonismo é oposição, luta, ação divergente, prevista nas duas Constituições, ao assegurarem o regime representativo de base popular, ... a plurareito de greve políticos, o direito de representação, o dição imprecisa, a prática cecesse o decreto-lei, na sua concepderia gerar antagonismos desses princípios constitucionais po-

Cita, a seguir, a puniveis, sem crime." 21

- qual seriam antagoninião do Senador Eurico Rezende, para governo no que tange Imprensa e o Ministro a gastos militares; a divergência entre a debate parlamentar federal das políticas milita ARENA e o MDB sobre a direção dor Rezende, seriam "ares etc. Tudo isso, segundo o Senaenquadrar alguém na "antagonismos internos" que poderiam

Ainda antagonismoqui, há flagrante incompreensão. Já vimos que o

atitude deliberada e contestatónal, in Rev. de Informaç̃o, Inconstitucionalidade da Lei de Segurança Nacio- 
ria aos Objetivos Nacionais e, portanto, não se confunde com a simples oposição democrática. É o que, por outras palavras, declarou o Presidente Médici: "Admite-se a oposição ao Governo, mas não a contestação ao regime."

A única objeção que se poderia fazer à Lei de Segurança seria de ordem geral, a de inserir no texto definições cujo alcance demandaria maiores esclarecimentos. Mas a exegese poderá valer-se das fontes em que a lei foi inspirada, especialmente a doutrina da Escola Superior de Guerra, que outra não é senão a que estamos delineando. ${ }^{22}$

\section{8 - A INTERPRETAÇÃO DO SUPREMO}

TRIBUNAL FEDERAL

Com base no art. 58 da Constituição Federal, o Presidente da República baixou o Decreto-lei $n$ ? 322 , de 7 de abril de 1967, que regulou o reajustamento de aluguéis e, no art. $5{ }^{\circ}$, tratou da purgação da mora nas locações para fins não residenciais.

Apreciando este último dispositivo, o Supremo Tribunal Federal o julgou inconstitucional, após analisar a faculdade do Presidente da República de expedir decreto-lei em matéria de segurança nacional, cujo conceito aquela alta Corte procurou firmar. Eis o que dispõe a ementa do acórdão então proferido: 23

"Decreto-lei no regime da Constituição de 1967.

1 - A apreciação dos casos de "urgência" ou de "interesse público relevante", a que se refere o art. 58 da Constituição de 1967, assume caráter político e está entregue ao discricionarismo dos juízes de oportunidade ou do valor do Presidente da República, res-

22 A ESG foi criada justamente para estudar os problemas da segurança nacional, na acepção moderna. A sua finalidade, segundo a lel que a instituiu, de n? 785 , de 20 de agosto de 1949, é a de desenvolver e consolidar os conhecimentos necessários ao exercício de funções de direção e planejamento da segurança nacional. Houve depois certa evolução, e hoje a ESG está voltada também para o desenvolvimento e é, pois, uma escola de Politica Nacional.

Para quem se interessar pela organização e evolução da ESG, recomendamos o notável estudo publicado na revista da ADESG, Segurança e Desenvolvimento, no 132, 1969, de autoria do General Augusto Fragoso, intitulado "A Escola Superior de Guerra. Origem. Finalidade. Evolução".

23 In Rev. Trimestral de Jur.sprudência, vol. 45, agosto de 1968, pp. 559 e seguintes. 
salvada apreciação contrária e também discricionária do Congresso.

2 - Mas o conceito de "segurança nacional" não é indefinido e vago, nem aberto àquele discricionarismo do Presidente ou do Congresso. "Segurança nacional" envolve toda a matéria pertinente à defesa da integridade do território, independência, sobrevivência e paz do País, suas instituições e valores materiais ou morais contra ameaças externas e internas, sejam elas atuais e imediatas ou ainda em estado potencial próximo ou remoto.

3 - Repugna à Constituição que nesse conceito de "segurança nacional" seja incluído assunto miúdo de Direito Privado, que apenas joga com interesses também miúdos de particulares, como a purgação da mora nas locações contratadas com negociantes como locatários.

4 - O Decreto-lei no 322, de 7-4-67, afasta-se da Constituição quando, sob color de "segurança nacional", regula matéria estranha ao conceito desta."

O relator da decisão, Ministro Aliomar Baleeiro, em seu voto, assevera ainda que o conceito de segurança nacional deve inferir-se do que estabelecem os arts. 89 a 91 da Constituição. "Nesses três dispositivos," - acrescenta ele - "está dito que as medidas pertinentes ao estudo e organização se referem à terras de fronteiras e as operações militares, concessões de nicações, pontes e lugares estratégicos, transportes e comudos à defesa." e indústrias direta ou indiretamente vincula-

Os demais juízes, com exceção do Ministro Hermes Lima, dempanharam o voto do relator. O Ministro Evandro Lins ponderou que a segurança é o gênero, que envolve duas espécies: segurança externa e segurança interna. "De segurança externa evidentemente não se cuida, porque ela compreende problemas de guerra externa, de defesa do território nacional, o que não está em causa. A segurança interna compreende a defesa das instituições políticas do País, de modo geral, isto é, o sistema de governo, os Poderes da República, a Federação e tudo mais

Data venia de da segurança naciono eminentes cultores do Direito, o conteúdo maior amplitude. Os al, como foi inscrito na Constituição, tem 
gotam a relação conceitual de segurança. $O$ que ali se estatui é, de um lado, a responsabilidade de todos perante a segurança e, de outro, a composição e competência do Conselho de Segurança Nacional nesta matéria. Não se conceituou nesses dispositivos a segurança nacional, o que, aliás, só foi feito, depois, pela Lei de Segurança, conforme já frisamos.

Em suma, o que decidiram os ilustres Ministros é que não se pode estender o conceito de segurança nacional para incluir-se nele "assunto miúdo" de Direito Privado, como o de locação. Diríamos, no entanto, que ocorre, neste particular, o que se tem chamado publicização do Direito. Normas como as de legislação trabalhista e outras que tais deixaram de ter caráter exclusivamente privado, de livre convenção das partes, para transformarem-se em Direito Misto, de feição ambivalente, em que o Estado impõe restrições outras que não caberiam nas relações simplesmente particulares. São leis a que alguns autores denominam de "ordem pública", frisando as suas características predominantemente imperativas, nas quais não é lícito às partes transigirem.

Tais normas podem cair no âmbito da segurança quando visam promover medidas preventivas contra ameaças às "instituições e valores materiais e morais", de que fala o próprio acórdão que estamos comentando. $E$ isto acontece no caso das locaçôes de prédios, porque o assunto diz respeito ao problema habitacional, que, como os da educação, saúde e outros, está ligado às mais lídimas aspirações do homem e da comunidade. São necessidades relacionadas com o bem comum, a que o Estado deve prover, sob pena de gerarem frustrações e tensõẽs, com ameaças às instituições e àqueles valores. A crise habitacional, entre nós, com deficit de milhões de residências, se arrasta há decênios e já acarretou agitações sociais graves, inclusive com invasões de propriedades.

Dentro desse critério, o assunto tem repercussão na área da segurança, a qual, data venia, não pode ter o confinamento em que a colocaram os eminentes Ministros - de defesa das instituições e valores, no sentido estritamente militar.

9 - CONCLUSÃO

Os conceitos aqui emitidos são, na sua maioria, correntes na Escola Superior de Guerra, e para sua elaboração cooperamos como membro que somos, há cerca de oito anos, do corpo 
permanente daquela instituição. Como tais conceitos já foram incorporados à nossa legislação e se transformaram em normas de larga repercussão na vida nacional, pareceu-nos útil divulgar aquilo a que poderíamos chamar os antecedentes históriramos que devem ser levados em conta na exegese da lei. Espetextos, evitando as trabalho concorra para a elucidação desses ensejado. 